\title{
Peer Observation of Teaching: Reflections of an Early Career Academic
}

\author{
Rajaraman Eri \\ School of Health Sciences, University of Tasmania, Launceston, Australia \\ *Corresponding Author: rderi@utas.edu.au
}

Copyright (C) 2014 Horizon Research Publishing All rights reserved.

\begin{abstract}
Peer observation of teaching (POT) is a reciprocal process where a peer observes another's teaching (classroom, virtual, on-line or even teaching resource such as unit outlines, assignments). Peers then provide constructive feedbacks that would enable teaching professional development through the mirror of critical reflection by both the observer and the observee (Brookefield, 1995). Peel (2005) through her own experience of POT as a new lecturer describes it as a multifaceted process that involves technical knowledge, class room dynamics, personal growth and change. Barnett (1992) in fact argues for the case of peer observation by declaring "academic knowledge does not count as knowledge without it having been subjected to some kind of peer evaluation". As a new academic with very little idea about good practice of teaching, the whole process of POT opened my eyes to achieve a greater transformation. In this essay, I describe the process of peer observation narrated as my reflection. I had experienced the best of what POT had to offer in the form of providing and receiving valuable feedback from my peers.
\end{abstract}

Keywords Peer Observation of Teaching, Feedback, Peer Evaluation

\section{Introduction}

What is peer observation of teaching (POT) and why is it necessary?

I understand POT as a reciprocal process where a peer observes another's teaching (classroom, virtual, on-line or even teaching resource such as unit outlines, assignments). Peers then provide constructive feedbacks that would enable teaching professional development through the mirror of critical reflection by both the observer and the observee (Brookefield, 1995). Peel [11] through her own experience of POT as a new lecturer describes it as a multifaceted process that involves technical knowledge, class room dynamics, personal growth and change. Barnett (1992, p.123) in fact argues for the case of peer observation by declaring "academic knowledge does not count as knowledge without it having been subjected to some kind of peer evaluation"

Some of the benefits associated with POT are:

A. Enhancement of teaching quality and skills

B. Gaining confidence in teaching methods

C. Acquiring new ideas for more efficient teaching

D. Sharing of teaching methods and practices

E. Assurance of continued commitment to teaching and learning (Bell \& Mladenovic, 2008).

While there are a number of benefits of POT, the risks should also be borne in mind. Gosling [7] discusses these risks in his essay and identifies three important components as risk. They are complacency, conservatism and unfocussed nature in some instances. These factors will be considered during our interaction and further peer observation.

\section{Processes and Results}

\section{Setting the plot for POT: Initial plan}

During the ELT 502 (one of the units associated with Graduate Diploma in University Teaching and Learning at the University of Tasmania, Australia) face-to-face session, we were asked to select our respective partners for peer observation process. In my particular case, I was initially going to choose one person - Dr NC, but, two additional lecturers joined our team to make it four. Before the conclusion of our session for ELT 502, our team got finalised. When I searched for an effective size for POT, there doesn't seem to be any particular number favoured. A number of studies in POT suggest that it can be done in pairs or small groups (Donnelly, 2007; Gosling, 2002; D’Andrea, 2002; McMahon and O’Neil, 2007)

\section{Awesome Foursome: It takes four for POT}

I need to introduce my colleagues here to get a picture of one aspect of POT, namely choosing observers in different subject areas. My three colleagues were Dr. NC, a history $\mathrm{PhD}$, currently a lecturer in undergraduate preparatory program (UPP), Ms. LE, a master's degree holder in information technology, currently a staff librarian and $\mathrm{Mr}$. 
$\mathrm{AB}$, a fire fighter by profession, currently a lecturer in professional fire-fighting techniques. I want to bring in the question of having observers that belong to my own subject area namely, biosciences or biology-related lecturers. In our particular batch of ELT 502, I had a choice of four Biosciences lecturers; all my colleagues available to me to choose as observers. I chose a different subject area person to be my observer thinking that it would be a better choice. Some authors have acknowledge this difficulty by mentioning the existence of "power" held by staff belonging to the same school or same area of teaching (Hatzipangos and Lygo-Barker, 2006). Retrospectively, I regret my decision and the reasons for that are explained later in this essay. The idea of peer observation between different subject matter people has been debated in literature (Gosling, 2005) but there is doesn't seem to be any consensus on this matter. Gosling [7] argues for the inclusion of someone who has some expertise in the same subject area.

\section{Stages of POT making}

In Figure 1, I have depicted the process of POT as I understood through the face-to-face days of ELT 502 and also available materials from the University of Tasmania (UTAS) resources and literature in this area. It involves a series of meetings between the observer and the observee. I have arbitrarily divided the process into 5 stages. The stages are explained as follows along with my notes from the journal exclusively maintained for the purpose

\section{Stage 1: Pre-Observation}

At this stage, we set ourselves a target of identifying the material $/ \mathrm{s}$ to be observed, time, date, venue and the design of the POT observation sheet. We initially emailed each other about the first meeting. NC took a leadership role in suggesting the venue for our initial meeting. It was agreed that we meet at the UTAS Cafeteria.

I approached the first meeting with some possible dates for the type of observation I selected- namely, my lectures. The reason for choosing my lectures as my observation material is that I am relatively new to teaching and I haven't been assigned a role for unit co-ordination as yet. I had by then been invited by NC also to deliver a lecture for her UPP program students on the topic of viruses (biological, not computer). It was a blessing in disguise because I had two types of observations (large and small size class lectures) that could be arranged because of my lecture at UPP. Firstly, my biosciences classes - very large class, normally attended by around 250 students. Secondly, UPP classes are small sized, maximum of around 40 students.

On the first pre-observation day, we all met and exchanged the dates and venues for observations. Except LE who opted observations on both on-line lectures and face-to-face lecture, the rest of us preferred our class lectures. We noted each other's dates and venues and agreed that we would be sending the observation proforma (background information on the class size, composition and subject matter to be discussed in addition to the design of feedback sheet) within two weeks. Further, we also agreed on how we are going to send our feedbacks. Donnelly [5] vividly depicts the mechanics of POT where he paints this process as a "confidential" matter between the observer and the observee. In agreement to this, we all agreed to send our feedback to the person concerned followed by a group discussion.. 


\section{Observer}



\section{Observee}


Stage 4

Critical

Reflection

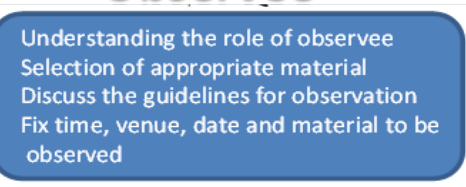

Be Punctual

Be as usual

Introduce the observer/s

Supply all the required materials

Direct the observer to the materials

Receive honest feedback

Read well and comprehend the notes

Clarify points with observer

Highlight special focus areas

Suggest meeting dates

Meet and discuss the notes

Clarify doubts face-to-face

Use your journal for the meeting

Acknowledge the support

Share mutual thoughts

\section{Stage 5}

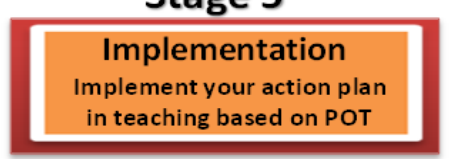

Figure 1. The process of peer-observation of teaching explained in 5 stages

\section{Ideal POT Pro-forma Design: Is there one?}

I started looking at a number of POT feedback designs. My search included UTAS resources, materials related to POT from a number of Australian Universities including University of Sydney, Macquarie University and Australian National University, and a number of overseas institutions such as Cambridge University, Hong Kong University to name a couple. When I looked at example designs, they provide me an overall idea but I was convinced that I need to design my own based on what I specifically want to focus on. As a new comer to UTAS and indeed to university teaching, it was a bit challenging. I had decided to seek assistance from my student evaluation of teaching and learning (SETL) records of my very first teaching unit in biosciences. I had collated the feedback from students and synthesised the points that were common. After all, all the four lenses of critical reflection namely, auto-biographical, student, peer and literature have to be considered in every stage of teaching and learning (Brookefield, 1995). At this stage I also think that my autobiographical lens was a bit jaundiced as explained later in this essay. In the end, I opted for a sandwich design that encompassed multiple assessment of teaching as seen in Appendix 1. The design specifically asked the observer to suggest ways to improve where they find a need.

\section{Stage 2: Peer Observation}

Easy Pot (On being an observer): My first exercise in POT happened in the way of being an observer in Dr NC's UPP class. As an observer, I wondered what I should equip myself with. Initially, I was under the impression that the feedback from the students in the form of emails, views expressed orally and appreciation in the form of applause were the major forms of feedback. Having received most of these forms of feedback, I was under the impression that best teachers are expected to get these forms of acknowledgement. My ego and understanding of teaching and learning took an unprecedented turn after undergoing ELT 501 and half of ELT 502. When I went through literature to prepare myself for NC's teaching observation, I reflected upon what I need to observe and indeed what I should learn and what I should observe and comment in a way that would enhance the professional practice of teaching.

One of the key points I have noticed in my preparation to observe is to view the whole exercise of observation from the perspective of a learner. My initial feeling of observation as a teacher with my own ideas embedded had given way to look at teaching as a platform for observing how effectively the teacher is engaging the students utilising a number of resources and opportunities available.

A number of studies have examined the exact nature of an observer and the common theory behind most of the studies describe that a peer observer has to establish a confidential and non-judgemental environment to be effective). Further, 
these studies also ascribe to the philosophy of POT as one that is friendly, formative, collaborative, explorative, honest, unbiased, reflective and non- judgemental (Donnelly, 2007; D'Andrea, 2002).

Next, I pondered over what materials and tools I should use during observation. $\mathrm{NC}$ had sent the observation pro-forma in detail before her class. It was very clear as to the class dynamics and also what she exactly needed in the form of assessment to improve her practice of teaching. Through Nicole's materials, I learnt quite a lot about how to provide as much information to an observer to maximise the benefits of POT.

The actual observation took place on the advised date. I went with the materials provided by $\mathrm{NC}$ in addition to materials for recording additional notes. I thought of recording my observation straight into the form provided but very quickly realised that it would not work. Hence, jotted down notes as I observed on a sheet of paper and later recorded my observation in the right format. One of the important points I reminded myself throughout the course of being an observer is to put myself in the shoes of the students listening to the class. One can easily forget this aspect because of easily getting absorbed into the subject matter being discussed in the class. I also made sure that I constantly observe the student reactions and gestures throughout the session.

After the first observation, I also gained some sort of perspective as to what is being observed. It helped in placing me in a better position for the observation of my other two colleagues. My second observation was that of another relatively small class sized practical session (20 students) done by LE at the library. The session was training in literature search for sociology students. Once again, just like the previous session, I spent a good hour to observe and record notes. In addition to this face-to-face class, I also observed the audio and video on-line versions of the same material by Louise. It was an interesting exercise because I realised the key differences between the face-to-face sessions and recorded on-line versions. The final lecture sessions I observed belonged to $\mathrm{AB}$. Once again, a small sizes lecture group consisting of seafarers aiming for a certificate in professional fire fighting skills through this class. Out of all these, the on-line observation was a bit difficult to observe as I had to imagine the student position and accordingly provide a feedback. Bennet and Barp [3] provide detailed outline of the significance and methodology for on-line observation and they conclude that many factors that relate to e-teaching need to be kept in mind in such a situation.

In all the four types of observations I made, I was able to reflect and learn more as well. The aspect of critical reflection throughout the process of POT has been well stressed by Hammersley-Fletcher and Orsmond [10] using data derived from two types of peer observation process in a post-1992 University. Through NC's lectures, I learnt how to be engaging in a heterogeneous of student group. Louise taught me a lesson or two in voice modulation and keeping it simple. AB's classes were very practical and based on real-life stories to which students connected well. One aspect none of colleagues implemented was to introduce the observers. The students looked at us a bit puzzled. So, I reminded myself that I need to introduce the observers so that students would know who they are and their purpose. Another important aspect of observation is to write down the comments as soon as possible. When I completed my observations, I had so many ideas and thoughts and innovative ways of expressing them to my colleagues. We may lose such valuable thought if we postpone these for too long.

The melting pot (On being observed): When it was my time to be observed, it all happened through two lectures. NC used my UPP lecture while LE and AB visited my rather large class (over 200 students). As mentioned in the above paragraph, I made sure that I introduced the observers before I began my lecture. I had also reminded myself that I need not make any extra efforts because I am being observed. I wanted feedback from a normal delivery of my lectures. To be honest, I didn't feel the presence of the observers throughout the class. The reason could be that the class size was bigger and the lecture theatre was large. My situation was in a bit of contrast to all the other observation I made where small classes were taught in compact lecture halls. In such a situation, the observer is quite visible to all and that can create a little of stress to the observee. The reason could be that the class size was bigger and the lecture theatre was large. Some points I followed during my lecture was that I wasn't providing a false impression about my gestures and body language. To that effect, I prepared myself for the observation to be a non-stressful affair and always kept in mind to be my normal self. The imagination of my observers sitting in my class and how I am going to introduce them and go on with the proceedings helped me shape the whole process well.

\section{Stage 3: Post-Observation}

I recorded elaborate notes during my observation and compiled my observations to all the three colleagues at different time points. I completed my observations on the forms designed by the observee. I needed to report the feedback in an efficient way that would convey the exact message in a constructive fashion. Donnelly [5] classifies the feedback into three divisions namely, "a review of criteria and agreements, a review of learning outcomes of the module and observed session, and a review of the lesson plan". While I do agree with the three divisions, it was indeed hard to provide feedback in such a stratified manner. I made special efforts on the areas where the observed wanted specific feedback. As this process of POT is mutual, I liked Gosling's idea of replacing the "giver" and "taker" notion to being equal share holders and hence mutual beneficiaries of the process. The process of composing the feedback took the maximum amount of time in the entire process. I must also confess that after finishing the first report, it was much easier. In that context, having to observe three instead of one was 
extremely beneficial. The feedback report had to keep a balance between being too critical to being too admiring. I didn't want to be making too many suggestions but precise ones with some form of substantiation. In a couple of instances, I had to revert to the observee to ask more details about certain aspects of my observation I thought I didn't understand fully. I believe it was a worthwhile exercise. For example, I wrote down some remarks about LE's lecture being a bit lacklustre and just wanted to confirm with her if she wasn't well on that day. It turns about to be the case and hence wasn't a real reflection of her personality. My feedback was designed to be constructive- starts with positive aspects of the observed session, then specific details requested by the observee and finally end in a positive note. I had realised through this process that explaining someone's shortcomings is not easy to present on a positive way. But, with each feedback, I got better and became more proficient in highlighting positive strengths and how some aspects can become better in my view.

\section{Stage 4: Critical Reflection}

The whole process of POT is aimed at improving the professional practice of teaching rather than being critical of someone's teaching methods. It is not a competition either and hence, a good platform was laid for constructive feedback. After I sent all the feedbacks and received mine by email one week prior to a meeting, a post-observation meeting happened at the University cafe. I need to describe a "Human feeling" here about my feedback. I had suggested some ways of improving to a couple of observees and the very thought of meeting them and discussing that provided some sort of bad feeling to me. I looked to literature about feedback in POT and the most heartening thing that came out of search was that constructive suggestions are part and parcel of the whole exercise and that I shouldn't be feeling bad about them. On the agreed date and time, all the four of us met and I lead the discussions by starting to share how I felt about the whole programme and the rest of our gang followed suit. Then, one by one we discussed about each other's strengths and what needs to be improved. One interesting aspect was that all of us had very similar feelings about the entire POT process. I felt we were talking more about our strengths than weaknesses.

I prepared myself well for this post-observation meeting by reading the feedback provided by my peers many times and similarly, I also read my own feedback to all the others one more time. This preparation made a lot of difference to our meeting. I was able to exactly correlate with what my colleagues were referring to and similarly could cite exact situations when I talked about my feedback to them. I discussed about one or two improvements to enhance the practice of teaching and explained what was really good in each of their classes and what I learnt from them as well. For example, I elaborated to Nicole about how well she engages both face-to-face plus on-line students at once. I commented on LE's efficient usage of colour highlighting in her presentation slides. For $\mathrm{AB}$, the biggest plus was his ability to roam around the class and keep them interested all the time with personal connection. In terms of peer observation of my lectures, I received mostly positive feedbacks and a couple of excellent suggestions such as increasing the usage of white board, and going slower when describing difficult acronyms. One can argue the efficacy of one-off observations but when the feedback is quite consistent from three different observers, it definitely indicates quality of the perceived strengths and improvement suggestions. We thanked each other for the valuable support through POT and promised email communication should we need to talk further. I receive one email about a further clarification post-meeting.

\section{Stage 5: Implementation}

An important aspect that I noticed during POT was the common threads that existed between the student assessment of my teaching through my SETL and peer-observation through POT. The qualitative comments made by students were made available to me recently for the same course I was observed. A couple of aspects for improvement were quite consistent between them. For example, both SETL feedback and POT feedback suggested that I could do better on specifically when I am referring to acronyms. So, when I combined these two lenses of reflection, I gained more in the form of suggestions to enhance my teaching practice. Based on the feedback, I started implementing specific areas in my subsequent lectures. My action-plan was drawn from the inspiration I derived being an observer and the valuable suggestion I received on being observed. I will detail one aspect that has borne fruits immediately. One of the suggestions provided to me was to increase the usage of the white board. I implemented that quite immediately and really felt that the students really appreciated that change. I started using the board especially when I state major acronyms (we do have quite few in biosciences). The usage of white board and additionally, the doc cam-overhead projector had definitely enhanced the student learning of my bioscience lectures.

Apart from specific feedback I received from my peers, the strategies I learnt from others also helped shape my lectures and fine tune some aspects of teaching. One example for that would be the observation I made during NC's lectures that you need to constantly think about the on-line listeners too. Many a times, I used to forget that group during my recorded sessions. Now, I am very cognizant of that group of listeners and cater to both the audience.

One important decision I regretted is the non-utilisation of one subject matter specialist as a POT observer. While the three of my peers did offer me valuable insights, I believe someone who knows the subject would have provided specific feedback related to how well we deliver a similar subject area as well. 


\section{Conclusions}

I am a new academic at UTAS with very little idea about what a good practice of teaching means. The whole process of ELT 502 workshops and POT opened my eyes to achieve a greater transformation. I had experienced the best of what POT had to offer in the form of providing and receiving valuable feedback from my peers. Bell and Madenovic ${ }^{[2]}$ report on a survey of POT from 32 observations. They conclude that $94 \%$ and $88 \%$ reported that they found POT valuable and made changes to their teaching because of POT respectively. I wasn't very convinced about this manuscript initially but after undergoing POT, I believe the authors were possibly quite right. An additional benefit from this exercise was the practice of the art of feedback writing.

I had contemplated on undergoing peer observation under one of our fellow School lecturers when I joined the school and just started teaching but due to the nervousness and the fear of my "imposter syndrome" getting an expose, I decided against it. After undergoing POT, I am very confident about the importance of POT and how one can take advantage of the process for best practice of teaching, career and teaching portfolio development. Since completing POT for ELT 502, I had requested one member of our biosciences team to observe and provide specific feedback to me. At least once in 3 years, I would like to continue POT. At a selfish level, I have gained valuable materials for teaching award applications.

In terms of wider applications of POT, the following questions need to be answered.

\section{Appendix 1}

Lecture Observation Worksheet

Lecturer: Course:

Date: Observer:
1. Can it be shared by all academics?

I strongly believe that POT will be a useful addition to all academics for improving their teaching skills irrespective of the amount of experience. In fact, I would strongly recommend POT as part of University academic introductory programs.

2. What do students get out of POT?

While there is no direct involvement of students in the process, the benefits for improved teaching and connection to students would directly have an impact on learning outcomes . Additionally, POT is a process not only to improve lecture delivery but also other areas of teaching such as unit outlines, on-line materials, examination questions, learning objective to name a few. Hence, multiple aspects of teaching and learning can be impacted by POT.

3. Is POT possible in a busy campus?

A reasonable question is the amount of time and processes involved in POT. While this manuscripts details the whole process in detail, one can involve just one peer in observation of a certain aspect that needs improvement.

Donnelly [5] in his essay on POT states" the scheme aids in the integration of theory and practice, how it focusses on the value of interdisciplinary learning and how the practice of new teachers to higher education can benefit"- I completely agree with him.

\begin{tabular}{|c|l|l|}
\hline \multicolumn{1}{|c|}{ Major Topic } & \multicolumn{1}{|c|}{ Sub-topics } & \\
\hline Content Organisation & Statement of purpose of the lecture & \\
\hline & Statement of learning objectives & \\
\hline & Relation to previous class & \\
\hline & Overview of the lecture & \\
\hline & Logical sequence of presentation & \\
\hline & Intonation and pacing of lecture & \\
\hline & Final summary & \\
\hline & & \\
\hline Presentation & Voice easily heard & \\
\hline & Effective intonation & \\
\hline & Entusiasm & \\
\hline & Simple, easy explanations & \\
\hline & Eye contact maintenance & \\
\hline & Body language & \\
\hline & Smooth transition between slides & \\
\hline & Examples \\
\hline & Restating important concepts & \\
\hline & Use of humour & \\
\hline & Time management & \\
\hline & Conclusion \\
\hline & Encourages student participation & \\
\hline & Student attention & \\
\hline & $\begin{array}{l}\text { Interaction with students } \\
\text { throughout the lecture }\end{array}$ & \\
\hline
\end{tabular}




\section{REFERENCES}

[1] Bell M. Peer observation of teaching in Australia. Learning and Teaching Support Network Generic Centre, UK; 2002.

[2] Bell A, Mladenovic, R. The benefits of peer observation of teaching for tutor development. Higher Education. 2008; 55 (6): 735-752.

[3] Bennett S, Barp D. Peer observation - a case for doing it online. Teaching in Higher Education. 2008; 13 (5): $559-570$.

[4] Brookfield S. Becoming a critically reflective teacher. SanFrancisco: Jossey-Bass; 1995.

[5] Donnelly R. Perceived impact of peer observation of teaching in higher education. International Journal of Teaching and Learning in Higher Education. 2007; 19, 117-129.

[6] D'Andera V. Peer review of teaching in the USA. Teaching and Learning Support Network. online access at www.heaacdemy.ac.uk/resources; 2002

[7] Gosling D. Models of peer observation of teaching.

Teaching and Learning Support Network. online access at www.heaacdemy.ac.uk/resources; 2002.

[8] Gosling D. Peer observation of teaching. SEDA paper 118; Staff and Educational Development Association; 2005.

[9] Hammersley-Fletcher L, Orsmond P. Evaluating our peers: is peer observation a meaningful process. Studies in Higher Education. 2004; 29 (4): 489-503.

[10] Hatzipanagos S, Lygo-Baker S. Teaching Observations: A meeting of Minds? International Journal of Teaching and Learning in Higher Education. 2006; 17(2): 97-105.

[11] Peel D. Peer observation as a transformatory tool? Teaching in Higher Education. 2006; 10(4): 489-504

[12] McMahon T, Barrett T and O'Neill, G. Using observation of teaching to improve quality-finding your way through the muddle of competing conceptions, confusion of practice and mutually exclusive intentions. Teaching in Higher Education. 2007; 12(4): 499-511.

[13] Shortland S. peer observation: a tool for staff development or compliance? Journal of Further and Higher Education. 2004; 28(2): 219-228.

[14] University of Tasmania Teaching and Learning website on peer review:http://www.teaching-learning.utas.edu.au/profes sional-development/self-peer-assessment 